\title{
Pregnancy of unknown location
}

\author{
Tal Milman MD, Melissa Walker MD MSc, Jackie Thomas MD MSc
}

Cite as: CMAJ 2020 September 28;192:E1132. doi: 10.1503/cmaj.200142

\section{1} Pregnancy of unknown location occurs in $10 \%$ of pregnant patients undergoing transvaginal ultrasound in the first trimester

Patients presenting with a positive pregnancy test and vaginal bleeding or pelvic pain routinely undergo transvaginal ultrasound as the standard diagnostic assessment. Pregnancy of unknown location is a classification that describes patients with a positive beta-human chorionic gonadotropin ( $\beta$-hCG) test without ultrasound findings of intra- or extrauterine pregnancy. ${ }^{1-3}$ The pregnancy of unknown location may be a viable or nonviable intrauterine pregnancy or ectopic pregnancy, or may resolve without its location ever being identified..$^{1-3}$

2 Gynecology consultation is indicated if history and physical examination at any encounter suggest ectopic pregnancy

Ectopic pregnancy occurs in $8 \%-14 \%$ of pregnancies of unknown location, compared with $2 \%$ in all pregnancies, ${ }^{3}$ but risk of rupture is low (2-3/1000 pregnant people). ${ }^{4}$ Asymptomatic patients should receive written information outlining symptoms that should prompt medical attention; an information sheet is provided in Appendix 1 (available at www.cmaj.ca/ lookup/doi/10.1503/cmaj.200142/tab-related-content). ${ }^{5}$ Persistent or worsening pain, signs and symptoms of hemodynamic compromise or hemoperitoneum require urgent evaluation. ${ }^{1,5}$

\section{3}

All patients with pregnancy of unknown location require a repeat $\beta$-hCG test $\mathbf{4 8}$ hours after initial testing

The ratio between $2 \beta$-hCG measurements 48 hours apart stratifies risk of ectopic pregnancy. ${ }^{1,2,5} \mathrm{~A}$ ratio greater than 1.63 suggests an intrauterine pregnancy, and patients should have a repeat transvaginal ultrasound in 1 week. A ratio of less than 0.5 suggests a failing pregnancy of unknown location that will resolve without intervention. All that is required is a serum $\beta$-hCG test in 14 days to ensure pregnancy resolution, and repeat transvaginal ultrasound is not indicated. Ratios between 0.5 and 1.63 are red flags, carrying a risk of ectopic pregnancy greater than $5 \%$. Close follow-up in 48 hours with repeat transvaginal ultrasound and $\beta$-hCG is essential. ${ }^{2}$ A management algorithm with thresholds, adapted from the National Institute for Health and Care Excellence in combination with management suggested by Tommy's National Centre for Miscarriage Research, is presented in Appendix 2 (available at www.cmaj.ca/lookup/doi/10.1503/cmaj.200142/tab-related-content).2,5

\section{4 \\ Empiric definitive management of pregnancy of unknown location is \\ rarely warranted}

Empiric management with methotrexate or laparoscopy before follow-up evaluation may result in harm to an intrauterine pregnancy, or unnecessary laparoscopy in pregnancies that will ultimately resolve without intervention. ${ }^{1,2}$

\section{5}

\section{Expectant management of pregnancy of unknown location is safe, provided} there is consistent follow-up

All patients, including those with low-risk pregnancies of unknown location, must be followed by the same health care team until the $\beta$-hCG test becomes negative or the pregnancy location is identified. ${ }^{1-3}$

\section{References}

1. Kirk E, Bottomley C, Bourne T. Diagnosing ectopic pregnancy and current concepts in the management of pregnancy of unknown location. Hum Reprod Update 2014;20: 250-61.

2. Bobdiwala S, Al-Memar M, Farren J, et al. Factors to consider in pregnancy of unknown location. Womens Health (Lond) 2017;13:27-33.

3. Reid S, Condous G. Is there a need to definitively diagnose the location of a pregnancy of unknown location? The case for "no". Fertil Steril 2012;98:1085-90.

4. Morse CB, Sammel MD, Shaunik A, et al. Performance of human chorionic gonadotropin curves in women at risk for ectopic pregnancy: exceptions to the rules. Fertil Steril 2012;97:101-6.e2.

5. Ectopic pregnancy and miscarriage: diagnosis and initial management. London (UK): National Institute for Health and Care Excellence; 2019.

Competing interests: None declared.

This article has been peer reviewed.

Affiliations: Department of Obstetrics and Gynaecology (Milman, Walker, Thomas), University of Toronto; Sinai Health System (Thomas), Toronto, Ont.

Correspondence to: Jackie Thomas, jackie.thomas@sinaihealthsystem.ca

CMAJ invites submissions to "Five things to know about ..." Submit manuscripts online at http://mc. manuscriptcentral.com/cmaj 